\title{
Study of the lgG endoglycosidase EndoS in group A streptococcal phagocyte resistance and virulence
}

\author{
Jonathan Sjögren ${ }^{1,2}$, Cheryl YM Okumura ${ }^{2,3}$, Mattias Collin ${ }^{1}$, Victor Nizet ${ }^{2,3}$ and Andrew Hollands ${ }^{2,4^{*}}$
}

\begin{abstract}
Background: The secreted enzyme EndoS, an endoglycosidase from Streptococcus pyogenes, hydrolyzes the Nlinked glycan of the constant region of immunoglobulin $\mathrm{G}(\mathrm{IgG})$ heavy chain and renders the antibody unable to interact with Fc receptors and elicit effector functions. In this study we couple targeted allelic replacement mutagenesis and heterologous expression to elucidate the contribution of EndoS to group A Streptococcus (GAS) phagocyte resistance and pathogenicity in vitro and in vivo.

Results: Knocking out the EndoS gene in GAS M1T1 background revealed no significant differences in bacterial survival in immune cell killing assays or in a systemic mouse model of infection. However, exogenous addition and heterologous expression of EndoS was found to increase GAS resistance to killing by neutrophils and monocytes in vitro. Additionally, heterologous expression of Endos in M49 GAS increased mouse virulence in vivo.

Conclusions: We conclude that in a highly virulent M1T1 background, EndoS has no significant impact on GAS phagocyte resistance and pathogenicity. However, local accumulation or high levels of expression of EndoS in certain GAS strains may contribute to virulence.
\end{abstract}

\section{Background}

Group A Streptococcus (GAS, S. pyogenes) is a humanspecific pathogen producing diseases ranging from pharyngitis and impetigo to severe, invasive conditions such as necrotizing fasciitis and streptococcal toxic shock syndrome [1]. Causing an estimated 500,000 deaths annually [2], GAS is one of the world's most important pathogens, reflecting its wide repertoire of virulence factors that interfere with host immune clearance mechanisms [3]. A hypothesized GAS immune evasion factor is the secreted enzyme EndoS, an endoglycosidase possessing a highly specific hydrolyzing activity toward the $N$ linked glycan of immunoglobulin G (IgG) [4]. The IgG heavy chain is $N$-glycosylated at asparagine 297 with a complex biantennary oligosaccharide that is crucial for the interaction with Fc gamma receptors (Fc $\gamma$ Rs) on phagocytic cells [5-7]. Experimentally, enzymatic deglycosylation of murine IgG can decrease complement

\footnotetext{
*Correspondence: anhollands@ucsd.edu

2Department of Pediatrics, University of California San Diego, 9500 Gilman

Drive, Mail Code 0687, La Jolla, CA 92093, USA

Full list of author information is available at the end of the article
}

activation, binding of IgG to FcyRs on macrophages, and antibody-mediated cytotoxicity [5].

EndoS is specific to native IgG, which is in contrast to many related endoglycosidases that requires denaturation of their glycoprotein substrates [8,9]. Furthermore, pretreatment of IgG with recombinant EndoS diminishes its ability to opsonize bacteria and interact with FcyRs on leukocytes [10,11]. The activity of EndoS on IgG heavy chain glycans is well characterized and conserved among GAS serotypes [12]. However, a potential role of endogenous EndoS expression by the GAS bacterium in phagocyte resistance and virulence has not been elucidated. We hypothesize that EndoS contributes to GAS virulence by hydrolyzing the $N$ linked glycan on IgG and thereby impairing antibody mediated functions in the immune system. Here we couple targeted allelic replacement mutagenesis and heterologous gene expression to study EndoS activity during bacterial-host cell interaction in vitro and in vivo.
C Biomed Central 


\section{Results}

Generation of EndoS mutants and heterologous expression

To investigate the contribution of EndoS to GAS and host-cell interactions an allelic replacement knockout in the M1T1 background was constructed and denoted 5448 $\Delta n d o S$. Heterologous expression of EndoS in a non-native EndoS producing GAS strain, NZ131 (serotype M49), was established by transformation of the EndoS expressing plasmid pNdoS. Loss- and gain-of-function was confirmed by Western immunoblot (Figure 1A) and IgG glycan hydrolysis assays (Figure 1B) [8]. As suspected no detectable EndoS was identified in the supernatants of the $5448 \Delta n d o S$ strain, and heterologous expression of EndoS in NZ131 was successful. In addition, higher levels of EndoS were observed in the overexpressing strain NZ131 [pNdoS] compared to the wild-type M1 strain 5448.

\section{Neutrophil killing assay}

The phagocytic resistance of GAS with and without EndoS contribution was investigated in a human neutrophil killing assay with GAS strains $5448 \Delta n d o S$ and wildtype 5448. Loss-of-function did not reveal significant difference in GAS resistance to phagocyte killing in the M1T1 background (Figure $1 \mathrm{C}$ ). In the same M1T1 background, exogenous recombinant EndoS, rEndoS, or PBS was used to pretreat plasma to investigate phagocytic resistance contribution of the enzyme itself. It was found that rEndoS increases GAS survival in the presence of neutrophils and plasma containing GAS antibodies (Figure 1D). The contribution of EndoS to GAS virulence was also studied in the less virulent strain NZ131 (serotype M49) in gain-of-function analysis. The results reveal that heterologous overexpression of EndoS in M49, NZ131[pNdoS] increased GAS resistance to killing by human neutrophils (Figure 1E).

\section{Monocyte killing assay}

As with neutrophil killing assays, no significant difference in bacterial survival was detected in the monocytic killing assays when comparing M1T1 GAS strain 5448 to the isogenic ndoS knockout strain (Figure 2A). Pretreatment of plasma with exogenous rEndoS resulted in a significant increase in GAS resistance to killing by monocytes (Figure 2B), as did heterologous expression of EndoS in the less virulent strain NZ131 (Figure 2C).

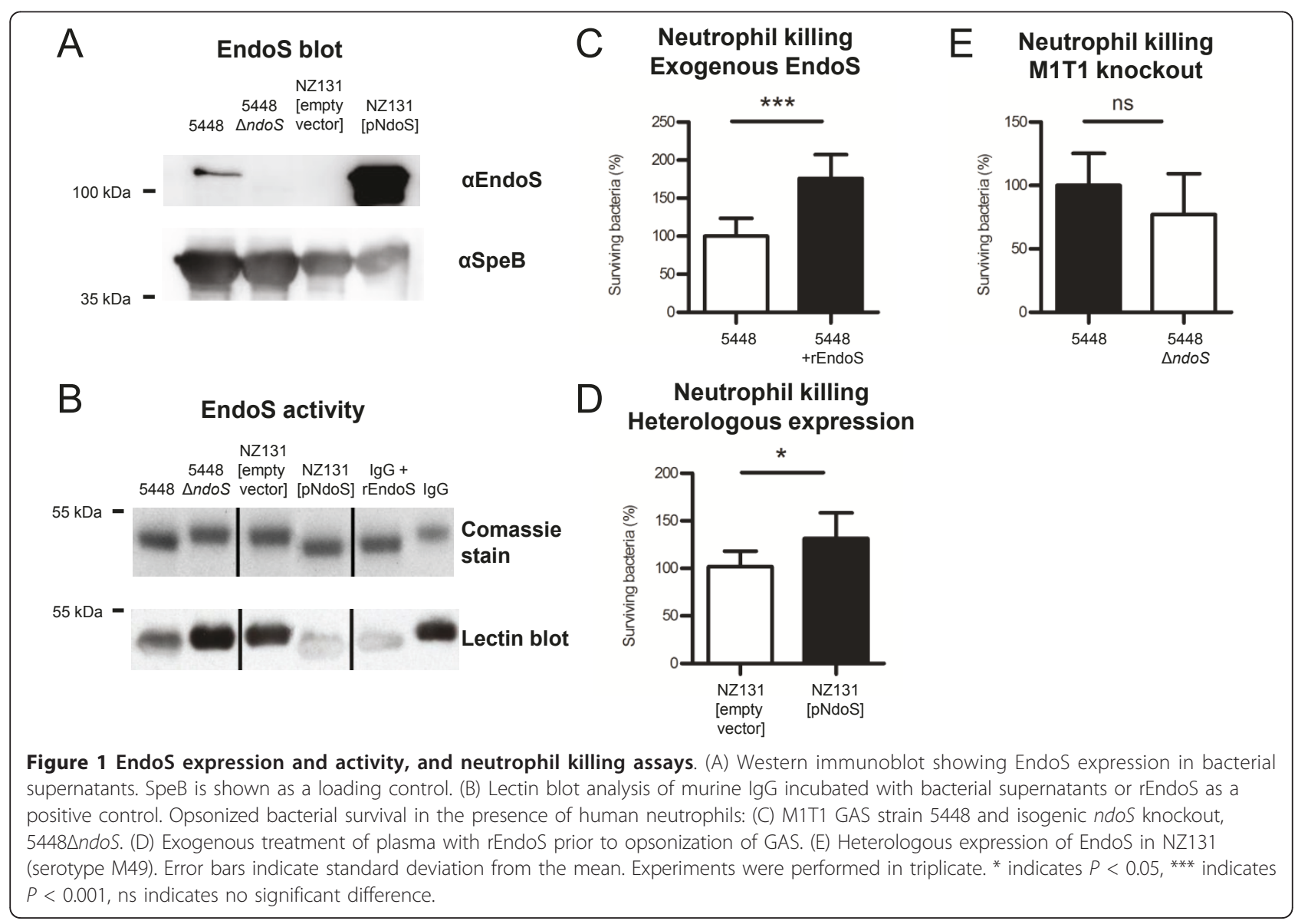



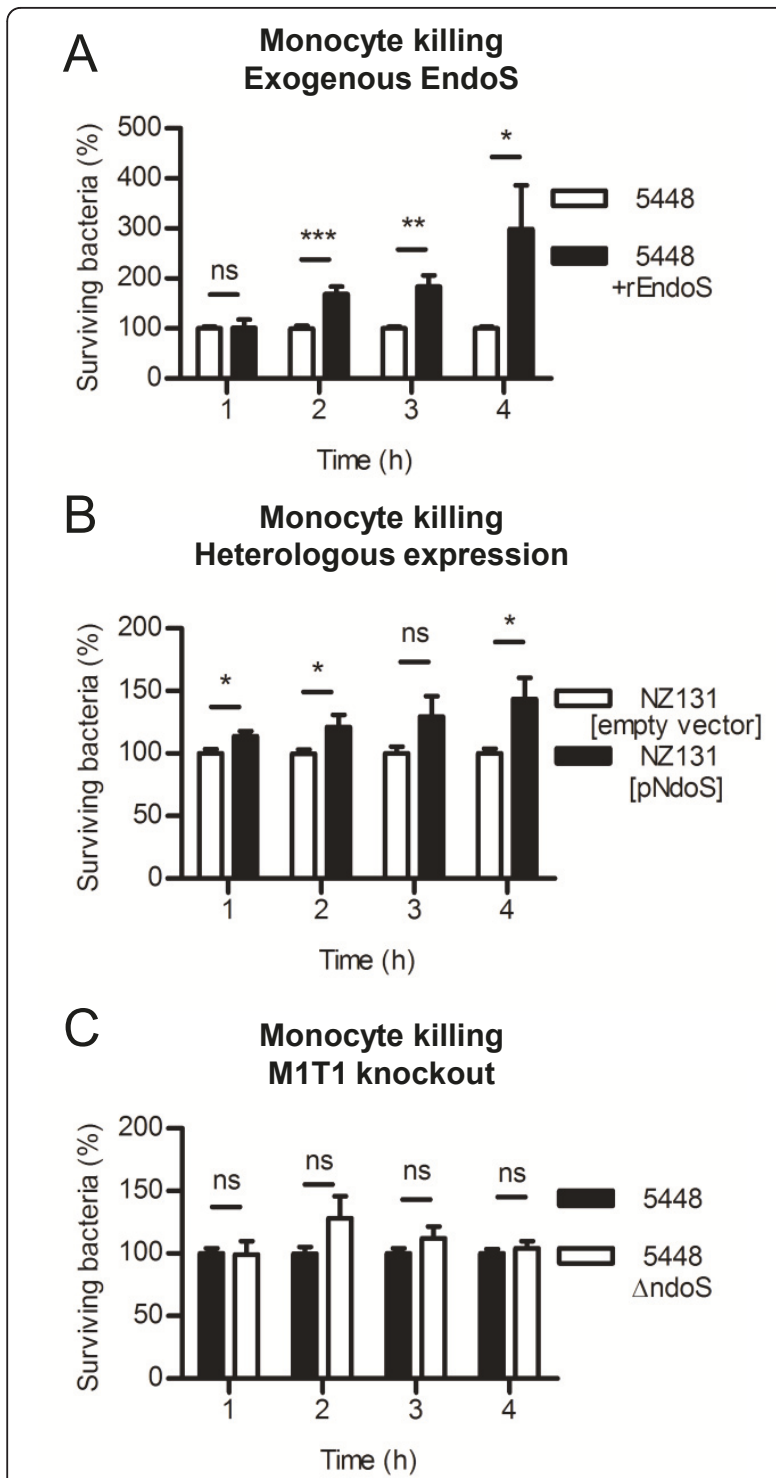

Figure 2 Opsonized bacterial survival in U937 monocytic cell killing assays. (A) M1T1 GAS strain 5448 and isogenic ndoS knockout, 5448 $\triangle$ ndoS. (B) Exogenous pretreatment of plasma with rEndoS prior opsonization of GAS. (C) Heterologous expression of EndoS in NZ131 (serotype M49). Error bars indicate standard deviation from the mean. ${ }^{*}$ indicates $P<0.05$, ${ }^{*}$ indicates $P<0.01$, *** indicates $P<0.001$, ns indicates no significant difference.

\section{In vivo mouse model}

Many major GAS virulence factors have been shown to decrease overall virulence when knocked out and studied in murine infection models [13-16]. It has also been shown that EndoS has activity on all subclasses of murine IgG [17]. Taken together, this led us to believe that the contribution of EndoS to GAS virulence could be studied in vivo. However, in this murine model of infection GAS strain $5448 \Delta n d o S$ showed no significant difference in virulence compared to wild-type 5448 (Figure 3A).

However, when we studied the less virulent GAS strain NZ131 (serotype M49) overexpressing EndoS, it was found that strain NZ131[pNdoS] showed increased virulence in vivo (Figure 3B) compared to wild-type NZ131[empty vector]. This may be a function of the relatively high level of expression of EndoS in NZ131 [pNdoS] compared to 5448 (Figure 1A).

\section{Discussion}

A single clone of the M1T1 serotype has disseminated globally during the last few decades to represent the leading cause of severe, invasive GAS infections [18]. The unique virulence of the M1T1 clone has been associated with many factors including the phage-encoded DNAse Sda1, allowing escape from neutrophil extracellular traps $[13,19,20]$, the streptococcal inhibitor of complement (SIC) protein, promoting serum and antimicrobial peptide resistance [14,21], pro-inflammatory and phagocyte resistance properties of the M1T1 protein $[15,22]$, high level expression of the pore-forming cytotoxin streptolysin O (SLO) [16], and a propensity for genetic mutations in the $\operatorname{cov} R / S$ regulatory locus promoting hypervirulence $[23,24]$. There exist many inherent limitations of modeling a secreted bacterial virulence factor in vitro and of the mouse as a surrogate host for GAS infection studies. However, our studies do strongly suggest that the endogenous expression of EndoS may be redundant or dispensable for M1T1 GAS phagocyte resistance and pathogenicity, since targeted mutation of the other factors described above do yield clear attenuation of virulence phenotypes in similar in vitro and in vivo assay systems.

Conversely, pretreatment of plasma containing antibodies against GAS with recombinant EndoS reduced opsonphagocytic killing of GAS, and heterologous overexpression of EndoS in a less virulent M49 GAS strain conferred increased phagocyte resistance and increased lethality in the mouse infection model. These results suggest that high level expression or local accumulation of EndoS in tissues could contribute to virulence in certain GAS strain backgrounds or infection scenarios, a subject that could merit future analysis in larger clinical or molecular epidemiologic surveys.

EndoS is highly conserved among GAS serotypes and can also be found in Streptococcus equi and zooepidemicus [12]. Therefore, it was somewhat surprising that we could not detect a significant contribution to GAS virulence in vivo. This may be due to the limitations of the mouse model used, and the expression levels of EndoS during the murine infection. The expression level of this enzyme during a human infection could have an impact on GAS immune cell killing resistance but this remains 

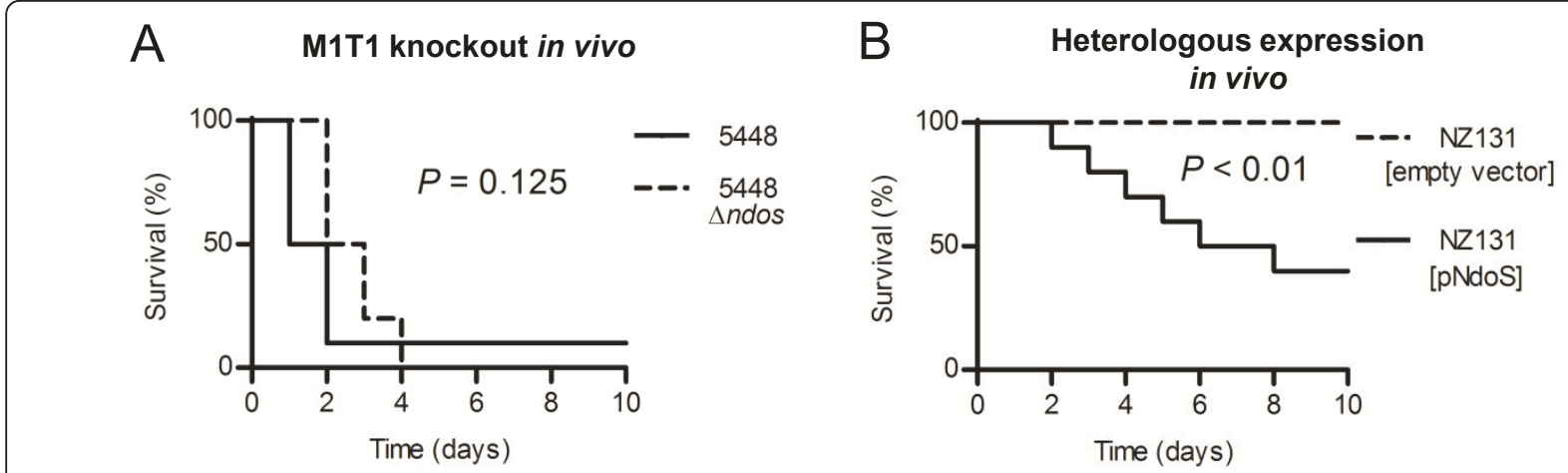

Figure 3 Survival curves of female CD-1 mice following intraperitoneal challenge with GAS. (A) M1T1 GAS strain 5448 and isogenic ndoS knockout, $5448 \Delta$ ndoS, at $2 \times 10^{7} \mathrm{cfu}$ with $5 \%$ mucin $(n=6)$. (B) Heterologous expression of EndoS in NZ131 (serotype M49) at $5 \times 10^{8} \mathrm{cfu}$ with $5 \%$ mucin $(n=10)$.

to be investigated. The specificity of EndoS activity towards IgG suggests that the enzyme may have an important role in the pathogenesis of GAS, yet to be discovered.

Finally, whether or not GAS can effectively deploy this unique enzymatic activity targeted IgG $\mathrm{N}$-glycosylation to promote its own survival in the host (as is intuitively appealing), the enzyme itself has already proven a promising lead biotherapeutic for treatment of antibodymediated inflammatory pathologies [17,25-29].

\section{Conclusions}

We conclude that in a highly virulent M1T1 background, EndoS has no significant impact on GAS phagocyte resistance and pathogenicity. However, our overexpression experiments could indicate that local accumulation or high levels of expression of EndoS can contribute to virulence in certain GAS strains, or in other infection scenarios than the systemic infection model used in this study.

\section{Methods}

\section{Bacterial strains and growth}

GAS strain 5448 (serotype M1T1, ndoS-positive) and GAS strain NZ131 (serotype M49, ndoS-negative) are well-characterized and were selected for use in this study [30,31]. Escherichia coli MC1061 was used as cloning tool [32]. The streptococcal and E. coli strains were propagated on Todd-Hewitt agar (THA). For selection, erythromycin (erm) was used at $5 \mu \mathrm{g} / \mathrm{mL}$ (5448), 2 $\mu \mathrm{g} / \mathrm{mL}(\mathrm{NZ131})$ and $500 \mu \mathrm{g} / \mathrm{mL}$ (MC1061). GAS and its isogenic mutant were grown in Todd-Hewitt broth (THB (Difco, Detroit, MI)) at $37^{\circ} \mathrm{C}$ without shaking. For in vitro and in vivo experiments, fresh overnight cultures were diluted 1:10 in THB and grown to mid logarithmic phase $\left(\mathrm{OD}_{600}=0.4\right)$ and resuspended in PBS, or in mid$\log$ supernatants for neutrophil assays with NZ131. For analysis of streptococcal supernatants, strains were grown in C-medium (0.5\% (w/v) Proteose Peptone no. 2 (Difco), $1.5 \%(\mathrm{w} / \mathrm{v})$ yeast extract, $10 \mathrm{mM} \mathrm{K}_{2} \mathrm{HPO}_{4}, 0.4$ $\mathrm{mM} \mathrm{MgSO}_{4}, 17 \mathrm{mM} \mathrm{NaCl} \mathrm{pH}$ 7.5) to maximize EndoS expression.

\section{GAS mutants}

EndoS is encoded by the gene $n d o S$. A precise, in-frame allelic replacement of $n d o S$ with chloramphenicol transferase, cat, was created in M1T1 GAS strain 5448 by a method previously described [13] and was denoted $5448 \Delta n d o S$. Briefly, a 798 bp fragment upstream, and 987 bp fragment downstream of $n d o S$ was amplified using polymerase chain reaction, $\mathrm{PCR}$, using primers $n d o S$-up-F-XbaI (GCATCTAGAGCTTGTCGGTCTT GGGGTAGC), ndoS-up-R (GGTGGTATATCCAGTGATTTTTTTCTCCATTTGGACACTCCTTATTTTT GGTACTAAGT C) and $n d o s$-dn-F (TACTGCGATG AGTGGCAGGGCGGGGCGTAAACAAAGTAACTT TCTTAGATAGCAACATT CAG), ndoS-dn-R-Bam HI (GCGGATCCGTTCTTGCGCCATGACACCTCC) respectively. The primers adjacent to $n d o S$ contained 30 bp overhang of the cat gene corresponding to the $5^{\prime}$ and 3 ' ends of cat, respectively. The upstream and downstream fragments were combined with the $650 \mathrm{bp}$ cat gene in a fusion PCR using primers ndoS-up-F-XbaI and $n d o S$-dn-R-BamHI. This triple fragment was digested using restriction enzymes $\mathrm{Xba \textrm {I }}$ and $\mathrm{BamH \textrm {I }}$ and ligated using T4 ligase into the temperature sensitive vector pHY304, bearing erythromycin resistance, to generate the knockout plasmid pHY-ndoS-KO. pHY-ndoS-KO was transformed into GAS 5448 by electroporation and transformants were grown at the permissive temperature of $30^{\circ} \mathrm{C}$ with erythromycin. Transformants were then grown at the non-permissive temperature of $37^{\circ} \mathrm{C}$ with erythromycin present to select for homologous recombination and integration of the plasmid into the genome. Single crossovers were confirmed by PCR analysis. Relaxation of the plasmid was carried out at $30^{\circ} \mathrm{C}$ with 
no antibiotic selection to allow the plasmid to reform, outside the chromosome. Growing the bacteria at $37^{\circ} \mathrm{C}$ without antibiotic pressure resulted in loss of the plasmid. Finally, screening for erythromycin sensitive colonies was used to identify double crossover events and allelic replacement mutants were confirmed by PCR. In frame allelic replacement $n d o S$ mutant, $5448 \Delta n d o S$, was confirmed by multiple PCR reactions showing the insertion of the cat gene and absence of the ndoS gene in the genome. Heterologous expression of EndoS in M49 GAS strain NZ131 was established by transformation with the EndoS expression plasmid pNdoS. ndoS was amplified from the M1 genome using primers ndoS-FEcoRI (GCGAATTCATGGATAAACATTTGTTGGTAAAAAGAAC) and $n d o s$-R-BamHI (GCGGATCCTTATTTTTTTAGCAGCTGCCTTTTCTC), digested with EcoRI and BamHI prior to T4-ligation into the expression vector $\mathrm{pDCerm}$, denoted $\mathrm{pNdoS}$. As a control, GAS strain NZ131 was transformed with the empty vector pDCerm to generate NZ131[empty vector].

\section{Western blot}

Supernatants from stationary phase (16 h) GAS strains 5448, 5448 $\Delta$ ndoS, NZ131[empty vector] and NZ131 [pNdoS] were precipitated with $5 \%$ final concentration of trichloroacetic acid and separated on a 10\% SDSPAGE gel and blotted onto a methanol activated PVDF membrane. The membrane was blocked in 5\% skimmed milk (Difco) for $1 \mathrm{~h}$ and washed $3 \times 10$ minutes in phosphate buffered saline, PBS $(137 \mathrm{mM} \mathrm{NaCl}, 2.7 \mathrm{M}$ $\mathrm{KCl}, 10 \mathrm{mM} \mathrm{Na}_{2} \mathrm{HPO}_{4}, 2 \mathrm{mM} \mathrm{KH_{2 }} \mathrm{PO}_{4}, \mathrm{pH}$ 7.4). The membrane was then incubated with polyclonal rabbit antiserum against rEndoS at 1:2000 dilution in 0.5\% skimmed milk and incubated for $1 \mathrm{~h}$ at $37^{\circ} \mathrm{C}$. The membrane was washed as before and incubated with goat anti-rabbit IgG conjugated with Horse radish peroxidase (Bio-Rad), at 1:5,000 in 0.5\% skimmed milk for $1 \mathrm{~h}$ at $37^{\circ} \mathrm{C}$. After washing, the membrane was developed using Supersignal West Pico Chemiluminescent (Thermo Scientific, Rockford, IL) and analyzed on a Chemidoc XRS (Bio-Rad, Hercules, CA).

\section{Lectin blot}

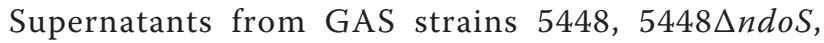
NZ131[empty vector] and NZ131[pNdoS] at stationary phase $(16 \mathrm{~h})$ was incubated with $1 \mu \mathrm{g}$ murine IgG (mIgG) for $2 \mathrm{~h}$ at $37^{\circ} \mathrm{C}$ at static conditions. As a positive control, IgG was incubated with $1 \mu \mathrm{g}$ rEndoS. The glycan hydrolyzing activity was analyzed with SDS-PAGE and lectin blot using biotinylated Lens culinaris agglutinin (LCA) (Vector Laboratories, Burlingame, CA). LCA lectin recognizes the $\alpha-1,3$ mannose residue found on the $N$-linked glycan on IgG. Briefly, the supernatants and mIgG were separated on 10\% SDS-PAGE gels, onestained with Coomassie blue and the other blotted onto Immobilon PVDF membranes (Millipore, Bedford, MA). The membrane was blocked in lectin buffer (10 mM HEPES, $0.15 \mathrm{M} \mathrm{NaCl}, 0,1 \%$ Tween 20, $0.01 \mathrm{mM}$ $\mathrm{MnCl}_{2}, 0.1 \mathrm{mM} \mathrm{CaCl}, \mathrm{pH}=7.5$ ) for 1 h. $10 \mu \mathrm{g} \mathrm{LCA} \mathrm{in}$ lectin buffer was incubated with the membrane for $1 \mathrm{~h}$ at RT. The membrane was then washed for $3 \times 10 \mathrm{~min}$ in lectin buffer and incubated with $2 \mu \mathrm{g}$ streptavidin linked HRP (Vector Laboratories) for $1 \mathrm{~h}$. After washing as above the blot was developed using Supersignal West Pico Chemiluminescent (Thermo Scientific) as described for Western blots.

\section{Neutrophil killing assay}

Neutrophils were purified from healthy donors using PolyMorphPrep-kit (Axis-Shield, Oslo, Norway) and RBCs lysed with sterile $\mathrm{H}_{2} \mathrm{O}$ as previously described [33]. Neutrophils were seeded at $2 \times 10^{5}$ cells/well in 96-well microtiter plates in RPMI.

Plasma was obtained from healthy volunteers as previously described [33]. All neutrophil and plasma donors exhibited high serum titer $(>1: 20,000)$ against serotype M1 and M49 GAS (Additional file 1 Table S1). GAS strains were grown as described and opsonized for $1 \mathrm{~h}$ at $37^{\circ} \mathrm{C}$ in $80 \%$ plasma, with or without pretreatment using recombinant EndoS (rEndoS) under rotating conditions. For pretreatment, $1 \mathrm{~mL}$ of plasma was incubated with $50 \mu \mathrm{g}$ of $\mathrm{rEndoS}$ or PBS (control) at $37^{\circ} \mathrm{C}$ for $2 \mathrm{~h}$ with rotation. The bacteria were then diluted to the desired concentration in RPMI with a final concentration of $2 \%$ plasma and added to the neutrophils at a multiplicity of infection (MOI) of 10 bacteria per cell. Control wells contained GAS in RPMI and 2\% plasma without neutrophils. The plate was centrifuged at $500 \times$ $g$ for $10 \mathrm{~min}$ and incubated for $30 \mathrm{~min}$ at $37^{\circ} \mathrm{C}$ with $5 \%$ $\mathrm{CO}_{2}$ before being serially diluted in sterile $\mathrm{H}_{2} \mathrm{O}$ and triplicate wells were plated on Todd-Hewitt agar (THA) plates for enumeration. Percent survival of the bacteria was calculated relative to control wells. Data from three separate experiments were normalized to 5448 or NZ131[empty vector] and combined.

\section{Monocyte killing assay}

The human monocytic cell line U937 was seeded at $5 \times$ $10^{5}$ cells/well in RPMI supplemented with $10 \%$ fetal bovine serum (FBS) in 24-well plates. GAS was grown and pre-opsonized in human plasma with or without rEndoS treatment, as described above. Bacteria were grown as described above and added to the U937 cells at $\mathrm{MOI}=10$ and incubated at $37^{\circ} \mathrm{C}$ with $5 \% \mathrm{CO}_{2}$. Samples were collected at $1,2,3$ and $4 \mathrm{~h}$ when monocytes were lysed with $0.025 \%$ Triton X-100 (MP Biomedicals, Aurora, $\mathrm{OH}$ ) and triturated vigorously. Surviving bacteria from triplicate wells were plated on THA for 
enumeration. Percentage of surviving bacteria was calculated relative to the initial innoculum. Data from at least three separate experiments were normalized to 5448 or NZ131[empty vector] and combined.

\section{Determination of donor serum titers}

Blood from healthy human donors was collected in glass venous blood collection tubes with no additives (BD Biosciences, San Jose, CA) and clotted at room temperature for $15 \mathrm{~min}$. Blood was centrifuged at 3,200 $\times \mathrm{g}$ for $10 \mathrm{~min}$ at $4^{\circ} \mathrm{C}$. The serum fraction was collected and stored at $-80^{\circ} \mathrm{C}$.

GAS strains NZ131 (serotype M49) and 5448 (serotype M1) were grown to mid-log phase in THB. Bacteria were resuspended in PBS and heat-killed at $95^{\circ} \mathrm{C}$ for 10 min. Heat-killed bacteria were mixed with a final concentration of $0.1 \mathrm{M} \mathrm{NaHCO} 3 \mathrm{pH} 9.6$ and $10^{6}$ bacteria per well were coated to 96-well high-bind ELISA plates (Costar, Cambridge, MA) at $4^{\circ} \mathrm{C}$ overnight. Plates were washed with PBS $+0.05 \%$ Tween (PBS-T) and blocked with $4 \% \mathrm{BSA}+10 \% \mathrm{FBS}$ in PBS-T for $1 \mathrm{~h}$ at $37^{\circ} \mathrm{C}$. Serum samples were diluted in blocking solution and incubated for $2 \mathrm{~h}$ at $37^{\circ} \mathrm{C}$. Plates were washed with PBS$\mathrm{T}$ and incubated with 1:5000 dilution of HRP-conjugated goat anti-human IgG antibody (Promega, Madison, WI) for $1 \mathrm{~h}$ at room temperature. Plates were washed five times with PBS-T and incubated with TMB substrate reagent (BD OptEIA TMB Substrate Reagent Set, BD Biosciences) at room temperature for $30 \mathrm{~min}$. The reaction was stopped with an equal volume of 0.2 $\mathrm{N}$ sulfuric acid, and the plate was read at $450 \mathrm{~nm}$. End point titer was determined as the dilution giving signal above a calculation cutoff determined using a mouse serum negative control and the calculation method described in [34].

\section{In vivo mouse model}

To evaluate the contribution of EndoS to GAS virulence in vivo, we utilized a murine model of systemic infection. GAS strains were grown as described and resuspended in PBS with 5\% mucin for an inoculum of $2 \times$ $10^{7} \mathrm{cfu}$ for WT M1T1 strain 5448 and isogenic mutant $5448 \Delta n d o S$, and $5 \times 10^{8} \mathrm{cfu}$ for NZ131[empty vector] and NZ131[pNdoS]. 8-10 week old female CD-1 mice (n $=6$ for $5448, \mathrm{n}=10$ for NZ131) were infected intraperitoneally with GAS strains and mortality was monitored daily for 10 days.

\section{Statistical analysis}

Cfu enumeration in neutrophil and monocyte killing assays were statistically analyzed by unpaired Student's $t$-test. Differences were considered significant if $P<0.05$. The in vivo results were evaluated with log-rank (Mantel-Cox) test for comparison of survival curves.
Differences in survival were considered significant if $P<$ 0.05 . All statistical analysis was performed using GraphPad Prism v.5 (GraphPad Software).

\section{Ethical approval}

Permission to collect human blood under informed consent was approved by the UCSD Human Research Protections Program. All animal use and procedures were approved by the UCSD Institutional Animal Care and Use Committee.

\section{Additional material}

Additional file 1: Table S1.

\section{Acknowledgements and Funding}

$\mathrm{AH}$ was supported by a Department of Employment Sciences and Technology (Australia) International Science Linkages grant to Prof. Mark Walker (U. Queensland) and VN. Additional support was provided by the Swedish Research Council (projects 2005-4791 and 2010-57X-20240 to MC), the Foundations of Crafoord (MC), Bergvall (MC), Österlund (MC), Wiberg $(M C)$, Söderberg $(M C)$, Kock (MC) the Swedish Society for Medicine (MC), the Royal Physiografic Society (MC), King Gustaf V's Memorial Fund (MC), and Hansa Medical AB (MC). CYMO is a San Diego IRACDA Postdoctoral Fellow supported by NIH Grant GM06852.

\section{Author details}

'Division of Infection Medicine, Department of Clinical Sciences, Lund University, SE-221 84 Lund, Sweden. ${ }^{2}$ Department of Pediatrics, University of California San Diego, 9500 Gilman Drive, Mail Code 0687, La Jolla, CA 92093, USA. ${ }^{3}$ Skaggs School of Pharmacy and Pharmaceutical Sciences, University of California San Diego, 9500 Gilman Drive, Mail Code 0687, La Jolla, CA 92093, USA. ${ }^{4}$ School of Biological Sciences, University of Wollongong, Wollongong, New South Wales, Australia.

\section{Authors' contributions}

JS participated in the design of the study, performed experiments and drafted the manuscript. MC and VN conceived of the study. CO performed experiments. AH designed the study and performed experiments. All authors read and approved the final manuscript.

\section{Conflicts of interests}

Patents for the in vitro and in vivo use of EndoS have been applied for by Genovis $A B$ and Hansa Medical $A B$, respectively. $M C$ is listed as inventor on these applications that are pending. Hansa Medical AB in part funded this study, but had no influence on the design of study, interpretation of data, or the final form of the manuscript. MC is a part time scientific consultant for Hansa Medical AB.

Received: 5 February 2011 Accepted: 27 May 2011

Published: 27 May 2011

\section{References}

1. Cunningham MW: Pathogenesis of group A streptococcal infections. Clin Microbiol Rev 2000, 13(3):470-511.

2. Carapetis JR, Steer AC, Mulholland EK, Weber M: The global burden of group A streptococcal diseases. Lancet Infect Dis 2005, 5(11):685-694.

3. Kwinn LA, Nizet V: How group A Streptococcus circumvents host phagocyte defenses. Future Microbiol 2007, 2:75-84.

4. Collin M, Olsén A: EndoS, a novel secreted protein from Streptococcus pyogenes with endoglycosidase activity on human IgG. EMBO J 2001, 20(12):3046-3055.

5. Nose M, Wigzell H: Biological significance of carbohydrate chains on monoclonal antibodies. Proc Natl Acad Sci USA 1983, 80(21):6632-6636. 
6. Krapp S, Mimura Y, Jefferis R, Huber R, Sondermann P: Structural analysis of human IgG-Fc glycoforms reveals a correlation between glycosylation and structural integrity. J Mol Biol 2003, 325(5):979-989.

7. Arnold JN, Wormald MR, Sim RB, Rudd PM, Dwek RA: The impact of glycosylation on the biological function and structure of human immunoglobulins. Annu Rev Immunol 2007, 25:21-50.

8. Collin M, Olsén A: Effect of SpeB and EndoS from Streptococcus pyogenes on human immunoglobulins. Infect Immun 2001, 69(11):7187-7189.

9. Tarentino AL, Plummer TH Jr: Enzymatic deglycosylation of asparaginelinked glycans: purification, properties, and specificity of oligosaccharide-cleaving enzymes from Flavobacterium meningosepticum. Methods Enzymol 1994, 230:44-57.

10. Collin $M$, Svensson MD, Sjöholm AG, Jensenius JC, Sjöbring U, Olsén A: EndoS and SpeB from Streptococcus pyogenes inhibit immunoglobulinmediated opsonophagocytosis. Infect Immun 2002, 70(12):6646-6651

11. Allhorn M, Olin Al, Nimmerjahn F, Collin M: Human IgG/Fc gamma R interactions are modulated by streptococcal lgG glycan hydrolysis. PLOS One 2008, 3(1):e1413.

12. Collin $M$, Olsén $A$ : Extracellular enzymes with immunomodulating activities: variations on a theme in Streptococcus pyogenes. Infection and Immunity 2003, 71(6):2983-2992.

13. Buchanan JT, Simpson AJ, Aziz RK, Liu GY, Kristian SA, Kotb M, Feramisco J, Nizet V: DNase expression allows the pathogen group A Streptococcus to escape killing in neutrophil extracellular traps. Curr Biol 2006, 16(4):396-400.

14. Pence MA, Rooijakkers SH, Cogen AL, Cole JN, Hollands A, Gallo RL, Nizet V: Streptococcal inhibitor of complement promotes innate immune resistance phenotypes of invasive M1T1 group A Streptococcus. J Innate Immun 2010.

15. Herwald H, Cramer H, Mörgelin M, Russell W, Sollenberg U, NorrbyTeglund A, Flodgaard $\mathrm{H}$, Lindbom L, Björck L: M protein, a classical bacterial virulence determinant, forms complexes with fibrinogen that induce vascular leakage. Cell 2004, 116(3):367-379.

16. Miyoshi-Akiyama T, Zhao J, Kikuchi K, Kato H, Suzuki R, Endoh M, Uchiyama T: Quantitative and qualitative comparison of virulence traits, including murine lethality, among different $\mathrm{M}$ types of group $\mathrm{A}$ streptococci. J Infect Dis 2003, 187(12):1876-1887.

17. Albert $H$, Collin M, Dudziak D, Ravetch JV, Nimmeriahn F: In vivo enzymatic modulation of $\mathrm{IgG}$ glycosylation inhibits autoimmune disease in an IgG subclass-dependent manner. Proc Natl Acad Sci USA 2008, 105(39):15005-15009.

18. Aziz RK, Kotb M: Rise and persistence of global M1T1 clone of Streptococcus pyogenes. Emerg Infect Dis 2008, 14(10):1511-1517.

19. Sumby P, Barbian KD, Gardner DJ, Whitney AR, Welty DM, Long RD, Bailey JR, Parnell MJ, Hoe NP, Adams GG, et al: Extracellular deoxyribonuclease made by group A Streptococcus assists pathogenesis by enhancing evasion of the innate immune response. Proc Natl Acad Sci USA 2005, 102(5):1679-1684.

20. Walker MJ, Hollands A, Sanderson-Smith ML, Cole JN, Kirk JK, Henningham A, McArthur JD, Dinkla K, Aziz RK, Kansal RG, et al: DNase Sda1 provides selection pressure for a switch to invasive group $A$ streptococcal infection. Nat Med 2007, 13(8):981-985.

21. Frick IM, Åkesson P, Rasmussen M, Schmidtchen A, Björck L: SIC, a secreted protein of Streptococcus pyogenes that inactivates antibacterial peptides. J Biol Chem 2003, 278(19):16561-16566.

22. Påhlman LI, Mörgelin M, Eckert J, Johansson L, Russell W, Riesbeck K, Soehnlein O, Lindbom L, Norrby-Teglund A, Schumann RR, et al: Streptococcal M protein: a multipotent and powerful inducer of inflammation. J Immunol 2006, 177(2):1221-1228.

23. Sumby P, Whitney AR, Graviss EA, DeLeo FR, Musser JM: Genome-wide analysis of group a streptococci reveals a mutation that modulates global phenotype and disease specificity. PLoS Pathog 2006, 2(1):e5.

24. Maamary PG, Sanderson-Smith ML, Aziz RK, Hollands A, Cole JN, McKay FC, McArthur JD, Kirk JK, Cork AJ, Keefe RJ, et al: Parameters governing invasive disease propensity of non-M1 serotype group A streptococci. J Innate Immun 2010.

25. Allhorn M, Briceno JG, Baudino L, Lood C, Olsson ML, Izui S, Collin M: The IgG-specific endoglycosidase EndoS inhibits both cellular and complement-mediated autoimmune hemolysis. Blood 2010, 115(24):5080-5088.
26. Nandakumar KS, Collin M, Olsén A, Nimmerjahn F, Blom AM, Ravetch JV, Holmdahl R: Endoglycosidase treatment abrogates IgG arthritogenicity: importance of IgG glycosylation in arthritis. Eur J Immunol 2007 37(10):2973-2982.

27. Collin M, Shannon O, Björck L: IgG glycan hydrolysis by a bacterial enzyme as a therapy against autoimmune conditions. Proc Natl Acad Sci USA 2008, 105(11):4265-4270.

28. Allhorn M, Collin M: Sugar-free antibodies - the bacterial solution to autoimmunity? Ann N Y Acad Sci 2009, 1173:664-669.

29. van Timmeren MM, van der Veen BS, Stegeman CA, Petersen AH, Hellmark T, Collin M, Heeringa P: IgG glycan hydrolysis attenuates ANCAmediated glomerulonephritis. J Am Soc Nephrol 2010, 21(7):1103-1114.

30. Chaussee MS, Ajdic D, Ferretti JJ: The rgg gene of Streptococcus pyogenes NZ131 positively influences extracellular SPE B production. Infect Immun 1999, 67(4):1715-1722.

31. Kansal RG, McGeer A, Low DE, Norrby-Teglund A, Kotb M: Inverse relation between disease severity and expression of the streptococcal cysteine protease, SpeB, among clonal M1T1 isolates recovered from invasive group A streptococcal infection cases. Infect Immun 2000, 68(11):6362-6369.

32. Casadaban MJ, Cohen SN: Analysis of gene control signals by DNA fusion and cloning in Escherichia coli. J Mol Biol 1980, 138(2):179-207.

33. Kristian SA, Datta V, Weidenmaier C, Kansal R, Fedtke I, Peschel A, Gallo RL, Nizet V: D-alanylation of teichoic acids promotes group a streptococcus antimicrobial peptide resistance, neutrophil survival, and epithelial cell invasion. J Bacteriol 2005, 187(19):6719-6725.

34. Frey A, Di Canzio J, Zurakowski D: A statistically defined endpoint titer determination method for immunoassays. J Immunol Methods 1998, 221(1-2):35-41.

doi:10.1186/1471-2180-11-120

Cite this article as: Sjögren et al: Study of the IgG endoglycosidase EndoS in group A streptococcal phagocyte resistance and virulence. BMC Microbiology 2011 11:120.

\section{Submit your next manuscript to BioMed Central and take full advantage of:}

- Convenient online submission

- Thorough peer review

- No space constraints or color figure charges

- Immediate publication on acceptance

- Inclusion in PubMed, CAS, Scopus and Google Scholar

- Research which is freely available for redistribution

Submit your manuscript at www.biomedcentral.com/submit
C Biomed Central 